\title{
RESUMEN DE REVISTAS
}

Pierre StTllmunkes: La classification des actes ayant force de loi en droit public français, en "Revue du Droit public et de la Science politiquen, marzo-abril de 1964, páginas 261-292.

La constitución de la $\mathrm{V}$ República ha introducido innovaciones que afectan a la caracterización de la ley y al reparto de materias que caen bajo su ámbito y el del reglamento; en definitiva, esas innovaciones se refieren a los límites del poder legislativo y ejecutivo.

Esquemáticamente la situación actual es la siguiente:

a) Al lado de la ley votada por e] Parlamento existe la ley aprobada por referéndum. El fundamento teórico es el mismo: la ley, expresión. de la voluntad general, manifesta- da de un modo indirecto y directo, respectivamente.

b) Dentro de las leyes parlamentarias se distinguen las ordinarias y las orgánicas. Estas se refieren a materias importantes y están sometidas obligatoriamente al control del Comité constitucional antes de su promulgación, en tanto que las primeras sólo lo están potestativamente.

c) El campo de aplicación de la ley no es ilimitado, como anteriormente, sino que queda circunscrito a unos límites fijados constitucionalmente. Lo que exceda de esos límites está reservado al poder reglamentario.

d) La delimitación de campos legal y reglamentario conduce a la utilización del criterio material para definir la ley parlamentaria $y$, sobre todo, la surgida de referéndum. Sin 
embargo, el criterio formal, cualidad de su autor (Parlamento o pueblo), tiene la primacia. En circunstancias excepcionales, cuando el Ejecutivo asume casi todos los poderes, la jurisprudencia ha acudido al criterio material con la finalidad de que puedan impugnarse los actos del Ejecutivo que versen sobre materias normalmente no de la competencia del legislativo.

e) Los actos del poder ejecutivo no tienen fuerza de ley. Esto no ofrece dudas por lo que se refiere a la actuación del poder ejecutivo en las materias que constituyen la reserva reglamentaria. El autor sostiene la misma tesis para los demás casos. Esta tesis, como es sabido, busca la posibilidad de impugnación jurisdiccional a que están sometidos los actos administrativos, pero no las leyes :

- Está prevista en la constitución la habilitación del Parlamento al Gobierno para que adopte medidas en materias que caen bajo el ámbito de la ley. Esta habilitación se hace por un plazo determinado, al final del cual el Gobierno debe presentar un proyecto de ley de ratificación. En tanto ésta no se realiza, las disposiciones del Gobierno permanecen como actos administrativos, susceptibles de impugnación jurisdiccional por infracción no sólo de la ley habilitante, sino también de la Constitución y de los principios generales del Derecho, según ha reconocido el Consejo de Estado. Como contrapartida, mientras dura la habilitación, el Parlamento no puede legislar en un sentido con- trario al contenido de aquélla.

- También tiene carácter de acto administrativo la disposición de]
Gobierno poniendo en vigor el proyecto de ley de finanzas cuando el Parlamento no se ha pronunciado sobre el mismo en un plazo de setenta dias.

- Igualmente el Consejo de Esta. do ha considerado que son impugnables las medidas adopta. das'por el Gobierno en materias propias de la ley cuando existe una habilitación otorgada por ley aprobada en referéndum. No se concibe esa habilitación como una delegación del poder legislativo, sino como una extensión del poder reglamentario. Cuestión aparte es la dudosa constitucionalidad de una tal habilitación.

ㄴ.

Francis-Padu Benort: Juridiction judiciare et juridiction administrative. "Juris Classeur Périodique. La Semaine Juridique». París, mayo 1964.

El concepto de upoder judicial» tiene su origen en el pensamiento de algunos lectores de Montesquieu. Este concepto, que no es sino una deformación del pensamiento filosófico de Montesquieu, no existe en la realidad de los hechos y la jurisdicción ejer. cida por jueces $y$ tribunales ha de ser estudiada como un servicio público más.

Otro lugar común denunciable es el del mito del llamado "derecho civil común», aplicable por princio a todo problema jurídico, cualquiera que sea su indole. Esta concepción es inexacta, técnica e históricamente, al menos en lo que se refiere al derecho administrativo.

La originalidad de los asuntos ad- 
ministrativos objeto de posibles litigios implica la existencia de un derecho propio, la falta de idoneidad del poder judicial para solucionar los pleitos administrativos y la necesidad de una jurisdicción especializada.

Finaliza Benoit su artículo, planteando la necesidad de que el Tribunal de conflictos francés revise sus puntos de vista y tome conciencia de que su misión no es meramente la de ser árbitro entre dos clases de jurisdicciones, sino la de garantizar el respeto al principio de división de poderes.

\section{\&}

J. San'toro y A. Allegrim: Aspetti della riforma del bilancio dello stato. "L'amministrazione italianay. Febrero 1964; pp. 130-138.

Se discute en Italia la propuesta de reforma del Decreto de 1923, que contiene las normas sobre la administración del patrimonio y Contabilidad General del Estado, en la parte relativa al presupuesto.

Tres son los puntos cardinales de la nueva Ley:

1.0 El año financiero a adoptar será el solar (en lugar del convencional que venía rigiendo hasta ahora); de esta forma se haría coincidir con el Presupuesto del Estado el de otros entes públicos, y con el de las Instituciones privadas, se posibilitaría la mejor inserción del Presupuesto en la Contabilidad Nacional y se lograria la armonización económica y fiscal con los países del Mercado Común.

2. Debería aprobarse con una sola ley los diecinueve estados de previsión correspondilentes a otros tantos Ministerios, aprobación que actualmente tiene lugar a través de dieci- nueve leyes distintas. La aprobación, en documento único, permitiría una gran economia parlamentaria de tiempo y energías, asi como el proceder a un mejor reparto de los gastos y al traslado de sumas de un Ministerio a otro.

3. Como innovación más destacada, se intenta la introducción del principio de funcionalidad en el presupuesto, que afectaría especialmente a los gastos al ser estimado desde el punto de vista funcional y económico, modificación justificada e impuesta por el carácter «productor» que ostenta el Estado moderno. De esta forma el presupuesto dejaría de ser «un documento extraño, incomprensible a los no competentes, dificil e ilógico para los mismos iniciados».

文

S. C. DUвE: La fonction publique et l'edification nationale dans les sociétés en transformation, en wRevue internationale des sciences sociales», Vol. XVI, núm. 2, 1964 ; páginas 250-257.

Aunque susceptibles de generalización, las observaciones del artículo están sacadas de la experiencia de la India.

La función pública es considerada como un elemento importante de la «élite» modernizadora e instrumento fundamental para el desarrollo de las naciones. El paso a la independencia de paises que durante años fueron colonias ha planteado varios problemas a la función pública, como en el caso de la India.

Los funcionarios constituian un subsector cultural prestigiado, en grado ascendente, según el puesto jerarquico, y ocupaban una situación in- 
cómoda e intermedia desde el punto de vista político: sospechosos para los nacionalistas por su colaboración con los extranjeros y nunca del todo tratados en plano de igualdad por los dirigentes occidentales.

Al conseguirse la independencia, la supremacia del hombre político y revolucionario fué evidente; sus deciciones, con frecuencia excesivamente personales, se adoptaban por caminos distintos a los habituales a la Administración y sin tener en cuenta los conocimientos de los funcionarios. Esto condujo a un recelo por parte de éstos y a una resistencia a adaptarse a las nuevas formas exigidas por la política.

La Administración durante la etapa colonial se ocupaba fundamentalmente del orden público y la cobranza de impuestos. Por ello, la función pública no se encontró preparada para las nuevas tareas del Estado, principalmente orientadas al desarrollo.

Los funcionarios tradicionales de administración general han of recido tenaz resistencia a todo cambio que implique una preponderancia de los técnicos especialistas. Esa resistencia se manifiesta también en una oposición a los distintos intentos de descentralización.

Poco a poco se ha ido reorientando la función pública, pero su pleno rendimiento ha venido impedido por implicaciones políticas y estructurales.

\section{म}

Realidades $y$ perspectivas del desarrollo económico. "Arbor», número 219 , marzo 1964.

Con este titulo la revista Arbor dedica un número monográfico al - desarrollo económico en España. E1 conjunto de trabajos recogidos va precedido por un prólogo del Comisario del Plan de Desarrollo, señor López Rodó, en el que resume las principales características del Plan español, destacando los aspectos sociales y humanos que el Plan implica.

Los trabajos se agrupan en tres apartados: Planteamiento cultural, social y económico. El sumario del número es expresivo de su contenido.

«E1 hombre español ante el Plan de Desarrollo Económico», por Mariano Yela. «Nivel de estudios del empresario españols, por Amando de Miguel y Juan J. Linz. «El Plan de Igualdad de Oportunidades», por Lorenzo Gelices. «Perspectivas fundamentales de la población y desarrollo económico», por Ramón Perpiñá y Grau. «Emigración y desarrollo económico en España», por Miguel Siguán. "La reestructuración profesional y el desarrollo económicon, por Antonio Perpiñá Rodríguez. «El problema social del desarrollo económicon, por Federico Rodríguez. «Incorporación del mundo rural al plan de Desarrollon, por Emilio Gómez Ayau. «Desigualdades sectoriales y regionales en la economía española», por José Giménez Mellado. "Desarrollo económico y distribución de la rentas, por Manuel Capelo Martínez. "Financiación de la empresa en una política de desarrollon, por Juan Sardá Dexeus. "La balanza de pagos y el desarrollo económicon, por Enrique Fuentes Quintana.

$$
\text { is }
$$

Louis Salderon: L'avenir de l'organisation. "Travail et méthodes», octubre, 1963, pp. 33-37.

El porvenir es de la organización. No es esta, sin embargo, una idea nueva. Ya Burnham anunció la ma- 
nagerial revolution, lo que pudiéramos llamar la era de la organización. Organizar es ordenar múltiples elementos con miras al logro de un fin dentro de una unidad dinámica; en este sentido la organización no es otra cosa que economía. Los elementos de la organización han existido siempre; sin embargo, desde la época ya clásica de Taylor, desde principios de siglo hasta nuestros días, la mutación de hechos e ideas, de medios y fines ha sido tal que el propio fin de la empresa se ha désplazado. De lo lucrativo se pasó a 10 productivo, y de aquí se tiende a lo humano; el trabajador, el obrero, se ha convertido en el fin de la empresa.

La organización del mañana supondrá, desde el punto de vista vital, la sustitución de un orden estático por una economía y armonía dinámica, y desde el punto de vista de métodos y técnicas, la concentración y la automatización, siendo de prever una complejidad y rigidez dificilmente evitables.

\section{i}

P. Dufourmantelle: Mission du service d'organisation. "Travail et méthodes». Octubre 1963, pp. 39-47.

Los problemas de organización que se plantean las empresas industriales son cada día más numerosos y complejos. Un servicio de organización, una Oficina de Organización y Métodos de trabajo, inserta en una organización cualquiera, debe estar dotada de un cierto espíritu crítico constructivo, debe poseer una técnica especializada y adoptar un punto de vista amplio, no particularista. Su competencia deberá extenderse al estudio de estructuras y costos, mantenimiento de calidades y standards de producción, a disminuir tanto como sea posible los stocks inmovilizados, a mantener y conservar los equipos de producción, a evitar el upapeleo» y la complejidad administrativa, a adoptar los métodos y técnicas de mecanización y automatización que sean justificados y rentables.

El éxito de una oficina de organización dependerá en gran medida de las siguientes circunstancias: apoyo que preste la dirección y jefaturas, intercambio de experiencias entre los diversos servicios, conocimiento que la dirección y los jefes jerárquicos posean de las técnicas básicas de la organización, selección de los propios organizadores, intercambio de experiencias con otros especialistas y existencia de un programa de trabajo.

\section{\&}

J. PRedseIl : Un nouvel homme de l'organisation. "CNOF, revue mensuelle de l'organisation», mayo 1964 , pp. 5-16.

A la visión pesimista de la organización, que denuncia sus contradicciones y absurdos, se opone una nueva visión esperanzadora: la del comienzo de una civilización. Las relaciones entre las organizaciones, Inicialmente industriales, $y$ el personal a ellas adscrito, han sufrido un proceso evolutivo: $1 .^{\circ}$, mantenimiento del orden ; $2 .^{\circ}$, organización científica del trabajo, y 3.\%, relaciones humanas (el individuo no es un dato más de la ecuación Industrial). Una cuarta etapa se inicia, la de la integración dentro de la sociedad de nuevas formas de producción que han de suponer un beneficio para el hombre, mediante el reparto de las riquezas que la ciencia y la técnica permiten crear con relativa facilidad. 
R. MonnIN : La decision dans les enterprises. "CNOF, revue mensuelle de l'organisation», mayo 1964, páginas 9-16.

Las decisiones - voluntad de imprimir una determinada dirección al futuro de una empresa con el fin de mantenerla en funcionamiento-pueden ser positivas y negativas. Su adopción está en función de la independencia de quien la adopta y de su posible alcance y repercusión. Son elementos comunes a toda decision, la iniciativa de la misma, sea o no provocada tal decisión por acontecimientos externos; la necesidad de información -el secreto de una dirección eficaz se halla en la documentación e información sobre la que se fundamentan las decisiones-; la preparación de la decisión mediante la valoración conjunta de los diversos materiales recopilados; finalmente, la adopción de la decisión con conciencla de que no ha de satisfacer a todos.

$$
\text { th }
$$

D. Pernin: Domaines d'application et coût de l'instrucion programmée. «Hommes et Techniques» número 230, enero 1964, pp. 41-47.

La enseñanza programada permite el aprendizaje de cualquier tipo o faceta del conocimiento siempre que sea susceptible de plasmarse en términos o símbolos racionales, por ejemplo, leyes, códigos, etc.

Un estudio del costo por alumno ha puesto de manifiesto que aun siendo éste considerable, en ciertas ocasiones resulta menor que el costo de las tradicionales técnicas de enseñanza.
N. A. CROWDER: Programmation linéaire et programmation intrinséque. "Hommes et Techniques» número 230, enero 1964, pp. 32-37.

El fin de la programación lineal consiste en conseguir que el alumno reaccione convenientemente a estímulos previamente seleccionados, emitiendo respuestas correctas en relación con los conocimientos que se le acaban de suministrar. Para ello, la programación lineal parte del desdoblamiento de la asignatura en diversas y breves etapas, repetición y estímulo psicológico del alumno que encuentra la respuesta correcta, pues si la programación ha estado bien realizada, las respuestas incorrectas serán infrecuentes o de mínima entidad.

Por el contrario, la programación intrínseca constituye una técnica en la que mediante el diagnóstico de las causas de los errores cometidos se facilita en el alumno la adquisición de los mecanismos mentales que le permitan encontrar la respuesta adecuada.

$$
2
$$

D. Pernin: Qu'est-ce que c'est l'instruction programmée? "Hommes et Techniques» núm 230, enero 1964; pp. 13-27.

Estamos ante una nueva técnica: el método del estudlo programado, mediante máquinas especializadas, nueva técnica pedagógica de inđudable valor, pues permite reducir el tiempo de aprendizaje en unos casos y mejorar la calidad de los conocimientos en otros. Supone un acercamiento más íntimo entre el alumno y el profesor que el facilitado hasta 
ahora por los libros y adapta la enseñanza al nivel de cada alumno. Estas máquinas están basadas en las siguientes funciones pedagógicas de la respuesta del alumno, prestación de la respuesta verdadera y almacenaje de secuencias.

La enseñanza programada ha supuesto la comprobación experimental de diversas técnicas, cuyos principios fundamentales son aún hipotéticos. Las primeras máquinas han aparecido en Norteamérica en 1960, habiéndose conseguido desde entonces, en diversas ocasiones, resultados espectaculares.

J. O. M., R. V., J. M. 